Bryant University

Bryant Digital Repository

Management Department Journal Articles

Management Faculty Publications and

Research

$5-4-2020$

\title{
Personality configurations in teams: a comparison of compilation and composition models
}

Kathryn Ostermeier

Bryant University, kostermeier@bryant.edu

Mark Davis

University of North Texas

Robert Pavur

University of North Texas

Follow this and additional works at: https://digitalcommons.bryant.edu/manjou

Part of the Business Administration, Management, and Operations Commons, and the Management Sciences and Quantitative Methods Commons

\section{Recommended Citation}

Ostermeier, Kathryn; Davis, Mark; and Pavur, Robert, "Personality configurations in teams: a comparison of compilation and composition models" (2020). Management Department Journal Articles. Paper 60.

https://digitalcommons.bryant.edu/manjou/60

This Article is brought to you for free and open access by the Management Faculty Publications and Research at Bryant Digital Repository. It has been accepted for inclusion in Management Department Journal Articles by an authorized administrator of Bryant Digital Repository. For more information, please contact dcommons@bryant.edu. 


\section{Team Performance Manag}

\section{Personality Configurations in Teams: A Comparison of Compilation and Composition Models}

\begin{tabular}{|r|l|}
\hline Journal: & Team Performance Management \\
\hline Manuscript ID & TPM-09-2019-0097.R1 \\
\hline Manuscript Type: & Research Paper \\
\hline Keywords: & Teams, Personality \\
\hline \multicolumn{2}{l}{} \\
\end{tabular}

\section{SCHOLARONE \\ Manuscripts}




\title{
Personality Configurations in Teams: A Comparison of Compilation and Composition Models
}

\begin{abstract}
Purpose: The purpose of this study is to examine the facilitating and inhibiting influence of team-level negative affectivity and conscientiousness on a dyad of emergent states, adopting and comparing both the composition and compilation perspectives.

Design/Methodology/Approach: Data were collected over three time points from 410 undergraduate students nested within cross-functional project teams $(\mathrm{N}=62)$. The data, including individual self-reports and judges' ratings of team performance, were aggregated to the team-level using both composition (mean) and compilation (skewness) approaches.

Findings: The findings indicate that mean-levels of negative affectivity were associated with decreased psychological safety. The use of skewed conscientiousness counterintuitively suggests too many highly conscientious members can also be detrimental to psychological safety. Psychological safety influences team potency and ultimately performance.

Originality/Value: The results of this study highlight that the aggregation approach utilized is important. For example, the use of skewed (but not mean-level) conscientiousness brought an undetected and counterintuitive relationship to light. Future research should utilize compilation approaches in addition to composition approaches.
\end{abstract}




\section{Introduction}

In competitive arenas, failure to utilize the diverse backgrounds and attributes of team members can have devastating effects: team chemistry matters (Mannix and Neale, 2005). Personality composition is particularly intriguing to team researchers given the evidence that personality traits are consistently related to individual performance (Barrick and Mount, 1991). Still, reviews of the link between personality and team performance have produced mixed results (Bell, 2007; Prewett et al., 2009). A clear majority of studies on team personality have adopted a composition perspective. The composition perspective assumes isomorphism wherein the convergence of a lower-level property yields a higher-level attribute that is essentially the same as the individual-level attribute. For instance, a composition view holds that team extraversion is largely the sum or average of individual-level building blocks of extraversion. However, Prewett et al. (2009) argue that the measurement practice of aggregating individual personality traits to the team level remains questionable as it fails to consider the team's distribution of scores.

In contrast, the compilation model is based upon the assumption of discontinuity. Rather than simple convergence, the higher-level phenomenon is viewed as a configuration of diverse and complex patterns of lower-level contributions (Kozlowski and Klein, 2000). For instance, Humphrey and colleagues (2007) proposed that minimizing conscientiousness variance should result in positive team performance. Stewart (2003) and others (Sinha et al., 2016) have described another form of compilation that employs skewness - or the measure of the symmetry of a distribution, whereby a positive skew has relatively few large values and a negative skew has relatively few small values (Hair et al., 2006) - as an indicator of imbalance or asymmetry in the distribution of team characteristics. Compilation models in general and skewness, in particular, have received much less attention than composition approaches in team research 
(Kozlowski and Chao, 2012). Considering alternative methodological approaches to measuring the effects of personality variables on team outcomes is important, as highlighted by the recent study by $\mathrm{Xu}$ and colleagues (2019). In this study, the authors found differing effects - and even directionality - between mean, minimum, and variance approaches to studying the relationship between team conscientiousness and team safety performance (Xu et al., 2019). This paper highlights the ramifications that methodological approaches can have in the team literature. Hence, a primary aim of this research is to compare the influence of asymmetry (via skewness) in team personality traits against the effects of traditional mean-based operationalizations of team personality.

In this study, we specifically target personality traits capable of impeding or facilitating the development of effective teams, negative affectivity and conscientiousness. Importantly, negative affectivity and conscientiousness provide a stark contrast in terms of valence. Given that traits are subject to different forms of emergence, observing a correspondence between composition (or compilation) measures and trait is more likely with the use of disparate rather than similar traits. Additionally, beyond the contrasting nature of conscientiousness and negative affectivity, both traits were chosen - out of the multitude of available individual differences - for several important reasons. First, both conscientiousness and negative affectivity are traits that have been documented to matter for team outcomes. As Humphrey and colleagues (2011) note, of the Big 5, conscientiousness appears to be particularly relevant for the study of team personality variance, since it captures the achievement-orientation and organization of team members (Costa and McCrae, 1992). Similarly, negative affectivity matters in teams, as teams engage in less prosocial behaviors when there is a tone of negative affectivity amongst the group (George, 1990). Second, both traits have been heavily studied via meta-analyses and conceptual 
reviews (e.g., Barrick and Mount, 1991; Dudley et al., 2006; Kaplan et al., 2009), making them interesting constructs for comparison. Lastly, as noted previously, both traits have been studied at the team level and, consequently, have instruments that are appropriate for aggregation.

Research and theory suggest that the effects of personality are generally transmitted to team outcomes through a mediation chain involving different team processes (Bell, 2007). Further, Prewett et al. (2009) found that team personality and team process variables are more strongly correlated than team personality and team outcomes. Accordingly, another aim of this investigation is to examine how personality effects are transmitted to performance through a specific dyad of team emergent states: psychological safety and team potency. Specifically, we posit that both conscientiousness and negative affectivity will influence psychological safety, which in turn influences team potency and ultimately team performance. Following other researchers who have shown that the compositional characteristics of team members (such as personality) influences team performance through affecting team processes (e.g., Barrick et al., 1998; Bradley et al., 2012; Mathieu et al., 2008), we theorize that both traits will influence psychological safety, although we take a more nuanced approach by delineating the effects through both composition and compilation approaches to aggregation.

Despite the sizeable research literature on psychological safety and team potency, to our knowledge this is the first study to examine the link between these constructs. However, there are several reasons that suggest why team psychological safety should influence team potency. First, considerable research underscores the significance of psychological safety in facilitating learning and information sharing (Frazier et al., 2017), processes essential to effective teams. Since team potency is the belief that one's team can be effective (Guzzo et al., 1993), it stands to reason that psychological safety - and the resulting team information sharing and learning - 
should increase the team's confidence that they can accomplish their goals and whatever challenges arise. Likewise, empirical findings reveal consistent, positive relationships between group potency and team effectiveness and scholars have called for additional research that considers the antecedents of group potency (Mathieu et al., 2008). Lastly, as team effectiveness is often operationalized as team performance (e.g., Hu and Liden, 2011), it follows that team potency should also consequently have a positive influence on team performance.

In sum, this investigation has two distinguishing features. First, we contrast a unique form of compilation emergence based on skewness with the conventional mean-based form of composition emergence to shed light on the influence of team personality on team processes. And, in contrast to the Xu et al. (2019) paper, we theorize and test our model at the team level, rather than theorizing or testing about cross-level interaction (i.e., a multilevel model, or nested approach). Second, we consider the transmission of personality effects (with both skewness and mean-based approaches) via a dyad of team states - psychological safety and team potency. We posit that both negative affectivity and conscientiousness influence psychological safety, which in turn influences subsequent levels of team potency and, ultimately, team performance.

\section{Theory and Hypotheses}

Strictly speaking, team processes reflect the interdependent acts of individual members that convert inputs into outcomes (Marks et al., 2001). Still, the interactions of individual members that think, feel, and behave are manifested as higher-level, emergent phenomena. Based on their team process typology - cognitions, motivational states, and behaviors Kozlowski and Ilgen (2006) identify a myriad of emergent phenomena that are linked to team effectiveness. One state deemed critical to the trusting and bonding requirements of effective teams is psychological safety (Ilgen et al., 2005). 
Team psychological safety is defined as a shared belief that the team is safe for interpersonal risk taking (Edmondson, 1999). In group interactions, psychological safety can foster the willingness to bring up and discuss difficult or potentially uncomfortable issues (WyssFlamm, 2002). In contrast, the absence of perceived safety can inhibit conversation and communication because members may be apprehensive about repercussions from peers (Frazier et al., 2017). The significance of psychological safety resides in its capacity to stimulate and support team learning. Because team members learn through conversation and sharing experiences, an unwillingness to share in the absence of psychological safety will effectively inhibit team learning (Kayes et al., 2005). Hence, we examine a contrasting pair of dark side versus bright side personality factors capable of hindering and facilitating psychological safety negative affectivity and conscientiousness. We begin with the traditional composition perspective to describe how mean level manifestations of the trait influence psychological safety. In turn, we argue that using a measure of distributional asymmetry such as skewness can provide important information about the influence of the trait that is distinct from the mean aggregated measure.

\section{Inhibiting Effects of Negative Affectivity}

Composition Perspective. Negative affectivity is a dispositional tendency to experience negative emotions including anxiety, frustration, and anger in a wide variety of settings and conditions (Watson and Clark, 1984). In general, individuals high in negative affectivity will experience greater levels of distress and dissatisfaction as they focus on the negative aspects of the world, their jobs, and themselves. In social interactions, these individuals are predisposed to react to neutral or negative feedback with feelings of resentfulness and persecution (Levin and 
Stokes, 1989). Hence, this individual difference variable can be a disruptive force in team interactions and a potential detriment to team performance (e.g., Barrick et al., 1998).

How might combined levels of individual negative affectivity give rise to psychologically unsafe team environments? First, given excessive sensitivity to unfavorable stimuli, detecting and drawing attention to team member failings and mistakes is likely to characterize high negative affectivity teams. Second, extreme rumination over others' or one's own flaws or missteps can exacerbate any initial negative sensitivity and increase the amount of time and effort required to recover from real or potential losses (Hobfoll, 1988). Third, any proclivity for interpersonal deviance and counterproductive work behavior may create conditions that team members will view as interpersonally threatening.

From a composition perspective, the mean trait score of team members represents a shared team attribute. The inferred process of emergence is one in which individual cognitions, perceptions, and behaviors linked to the trait converge overtime. Thus, to the extent that perceptions, cognitions, and behaviors stemming from negative affectivity are elevated among members, a strong aversion to admitting errors or acknowledging one's lack of understanding, hallmarks of psychologically unsafe conditions, is likely to emerge (Hood et al., 2016). On the bases of these arguments, we hypothesize:

Hypothesis 1: Mean aggregated negative affectivity is negatively related to psychological safety.

Compilation Perspective. To this point, the hypothesized effects of negative affectivity presume a bottom-up process wherein the lower levels of negative affectivity coalesce to yield a team-level property equivalent to the individual attribute. However, as Kozlowski and Klein (2000) note, lower-level characteristics do not always coalesce. For example, the performance of 
teams is frequently more than the combined performances of individual members. Rather, "team performance is often a complex function of specific individual and dyadic — networkedcontributions" (Kozlowski and Klein, p. 17). It follows that other team-level attributes may result from unique patterns or configurations of diverse lower level characteristics.

Researchers often focus on the variability of individual differences as a way of operationalizing team personality and capturing compilation differences undetected by the mean. (e.g., Barrick et al., 1998; Gonzalez-Mulè et al., 2014). However, Moynihan and Peterson (2001) argue that having a single member who is exceptionally high on a given trait is quite different from having a single member who is exceptionally low on that trait. Under those circumstances, using variance to represent a team-level trait could be misleading. Hence, they advocate for a configuration approach using other measures of the distribution. We propose that an asymmetric distribution of negative affectivity - specifically skewness - is a configural property of the team that provides a functional account for negative affectivity effects within teams.

Given one has a measure of team-level (mean) negative affectivity, what can skewness tell us about the relationship between negative affectivity and psychological safety? To begin, even if mean-aggregated levels of negative affectivity are equivalent, within-team distributional patterns of negative affectivity can differ substantially. For example, let's compare two, fivemember teams that have similar mean levels of negative affectivity. Team A has a positive skew, meaning they might have 3-4 members with low negative affectivity while the other 1-2 members have very high negative affectivity. Team B has a negative skew, whereby 1-2 members have low negative affectivity and the remaining 3-4 members are characterized by high negative affectivity. Because Team B has a critical mass (or a majority bloc) of high negative 
affectivity, this may invite a disproportionate number of interactions detrimental to the emergence of psychological safety. In contrast, even though Team A has an equivalent level of mean-aggregated negative affectivity, its small number of members with high levels of negative affectivity means that these members may fail to generate the same quantity or quality of interactions that give rise to psychologically unsafe conditions.

In general, the predicted effects of negative affectivity draw upon the classic adage "one bad apple spoils the barrel." Yet, even with the presence of a single team member characterized by negative affectivity, turmoil is not inevitable. Situational variables may inhibit behavioral expressions of negative affectivity (e.g., Felps et al., 2006). For example, group norms that proscribe unruly behavior can compel a single individual to act in positive fashion or at least suppress negative behavior. Consequently, an elevated (mean) level of negative affectivity due to a single member may be deficient as a gauge of team-level negative affectivity. However, multiple group members inclined toward negativity invite an adjustment of group norms capable of promoting rather than inhibiting negative behavior. In effect, once a critical proportion of members prone to negative affectivity is reached, any forces prohibiting negative behavior would be weakened. Indeed, negativity would be the norm. In sum, we contend that a distributional asymmetry in team negative affectivity, whether positive skew (a minority of high negative affectivity members) or negative skew (a majority of high negative affectivity members) will predict differences in psychological safety that go beyond that predicted by mean-aggregated levels of this trait. Thus, we hypothesize:

H2: Negative affectivity skewness is positively related to psychological safety, above and beyond mean level negative affectivity, where positive skewness (a minority of high 
negative affectivity members) is more beneficial than negative skewness (a majority of high negative affectivity members) for psychological safety.

\section{Facilitating Effects of Conscientiousness}

Composition Perspective. Although a recent meta-analysis of the antecedents of psychological safety included positive personality traits such as proactive personality, prior studies linking conscientiousness and psychological safety are conspicuously absent (Frazier et al., 2017). Still, several qualities of conscientiousness are potentially beneficial to psychological safety. First, the duty element (i.e., responsible, dependable, dedicated) predisposes conscientious members toward doing the right thing, for others as well as themselves (Moon, 2001). Moreover, conscientiousness is a consistent predictor of helping behavior (e.g., Hurtz and Donovan, 2000). As good citizens inclined to help and do the right thing, conscientious team members are more likely to refrain from behaviors such as interrupting others, dominating discussion, and fault-finding that make fellow members uncomfortable or insecure. Second, conscientious members tend to regard sharing relevant information with others as part of their duty. If so, their readiness to share information signals to other members that doing so is expected and appropriate. Third, highly conscientious members have a need for structure (Hogan and Ones, 1997) and try to manage uncertainty through this structure. Thus, they are more likely to support a clear structure for handling interpersonal concerns and conflict that may be detrimental to psychological safety. Altogether, the inclination toward doing the right thing, sharing information, and providing structure should support member perceptions that the team is safe for interpersonal risk-taking. Accordingly, an aggregation method that reflects high trait levels of conscientiousness (e.g., mean scores) should relate positively to psychological safety. 
Compilation Perspective. Based on the "bad apple" argument that describes the effects of negative affectivity, one might ask if the effect is the same for positive traits. Raver and colleagues (2012) offer some evidence that one individual's positive influence does not carry the same weight as another individual's negative attributes. In their investigation, the emergence of team helping norms was unrelated to the team maximum score for positive attributes such as conscientiousness. Thus, among their sample of teams the impact of a single individual with high conscientiousness was negligible.

Echoing earlier arguments, comparable levels of mean-aggregated conscientiousness can be achieved with and without a majority of highly conscientious members. In some instances, high mean-levels of team conscientiousness may simply reflect the presence of one highly conscientious member. The emergence process inferred from mean-aggregated measures may not be tenable for these teams. That is, the coalescence of cognitions, perceptions, and behaviors related to conscientiousness require more than one highly conscientious member. Hence, irrespective of the mean-level of conscientiousness in the team, the manifestation of team conscientiousness as well as its benefits likely occurs at some threshold (critical mass) of conscientious members, whereby a majority of conscientious members promote the behavior, information sharing, and planning conducive to psychological safety. Within team asymmetry or skewness in member conscientiousness, a compilation measure, is the appropriate means of capturing this process. Accordingly,

H4: Conscientiousness skewness is negatively related to psychological safety, above and beyond mean level conscientiousness, such that negative skewness in conscientiousness (a majority of highly conscientious members) is more beneficial than positive skewness (a minority of highly conscientious members) for psychological safety. 


\section{Team Potency}

Team Potency. Team potency and/or collective efficacy refer to the shared belief that the team can be effective (Guzzo et al., 1993). Both constructs are concerned with member beliefs about team capability, however, they differ in terms of specificity. Whereas team potency is viewed as a general belief emphasizing broad outcomes, collective efficacy beliefs are typically domain specific and refer to specific activities (Stajkovic et al., 2009). Given its capacity to predict team performance in a variety of contexts, the current study focuses on team potency. Prior research demonstrates that perceptions of team effectiveness and team potency are reciprocally and longitudinally related (Pearce et al., 2002). In effect, conditions that undermine or bolster member views of effectiveness are important to the development of potency. To the extent that psychologically safe or unsafe environments influence preliminary views of effectiveness, psychological safety will have an impact of team potency. We conjecture that open and trustful interactions wherein members can ask questions, report mistakes, or propose new ideas without fear of negative consequences, a core feature of psychological safety, is prerequisite for the perceived ability that the team is capable of handling challenges. Therefore, H5: Team psychological safety is positively related to team potency.

Team Performance. Team potency has received considerable attention as an antecedent to team performance. Undoubtedly, a consensus of team researchers considers potency as essential to effective teams. Prior research and meta-analytic evidence confirm that generalized potency is positively related to team performance (Gully et al., 2002). Accordingly, we expect team potency to relate positively to team performance.

H6: Team potency is positively related to team performance. 
A model depicting the hypothesized relationships is presented in Figure 1. Our analysis of the model, which includes control variables, incorporates the compilation (skewness) and composition (mean-aggregation) forms of negative affectivity and conscientiousness to verify that measures of skewness predict variation in psychological safety above and beyond the standard composition measure.

Figure 1

\section{Method}

\section{Sample and Data Collection}

We invited undergraduate business students to voluntarily participate in a study of Personality and Team Climate. Written informed consent was obtained from all participants that agreed to join in the research, and participation in the study was unrelated to the course grades. Ultimately, survey data were collected from 410 students comprising 62 teams across multiple sections of business policy courses from a large public university located in the southwestern region of the United States. As part of normal course procedures, students were randomly placed onto cross-functional project teams (by major) at the beginning of the course and worked with their teams from the start of a 15 -week semester. The average size of each team was seven members, with a range from five to eight members. To capture the emergent states of psychological safety and team potency required aggregating individual survey responses to the team level. Common aggregation statistics, $\operatorname{Rwg}_{(\mathrm{j})}(\mathrm{James}$ et al., 1984) and intraclass correlation coefficients (ICC) (Bliese, 2000), were used to justify aggregation.

Of the respondents, $53.9 \%$ were male and the mean age of respondents was 24 , ranging from 20 to 79 years $(S D=5.76)$. Team members completed two distinct self-report instruments 
during week three (time 1) and week ten (time 2) of the semester. At time 1, each student completed an initial survey that included basic demographic information along with measures of negative affectivity, conscientiousness, and psychological safety. At time 2, students completed measures of team potency. Lastly, independent judges' ratings of team performance were obtained during the final week of the semester (time 3). The time lag between emergent states and team performance represents an important procedural remedy to control for common method bias (Podsakoff et al., 2012). The Harman single factor technique is commonly used to estimate the degree to which biases caused by the survey method may be influential. This technique was implemented by conducting a principal component analysis approach using exploratory factor analysis on the constructs in this study. The analysis revealed that a single factor for the constructs explains $39 \%$ of the variation in the data and does not exceed the commonly used threshold of $50 \%$ to support detection of common method variance.

\section{Team Task}

During the course of the semester, each team completed a series of case-based assignments. The culmination of the course consisted of an integrated business case competition that required team members to merge insights and expertise from traditional functional boundaries (e.g., marketing, finance, etc.) to solve a real-world business problem. High performing teams that advanced to the final round of the competition were eligible for prize money and formal recognition by the institution.

\section{Measures}

Negative Affectivity. There are many instruments for measuring general affectivity. For example, the Positive and Negative Affect Schedule (PANAS) and the State-Trait Emotion Measure (STEM) are self-assessment scales that capture both transitory state and stable trait 
dimensions of moods and emotions (Levine and $\mathrm{Xu}, 2005$; Watson et al.,1988). The Negative Affectivity Scale (NAS) is a 21-item scale specifically designed to capture the global construct of negative affectivity - the dispositional tendency to experience aversive emotion states (Stokes and Levin, 1990). Validity studies demonstrate that the scale correlates significantly with measures of personality that assess specific aspects of negative affectivity such as neuroticism, anxiety, and anger (Levin and Stokes, 1989; Stokes and Levin, 1990; Sukhodolsky et al., 2001). Participants responded to NAS items on a 7-point agreement scale $(1=$ strongly disagree, $7=$ strongly agree). A sample item from the measure reads, "Things rarely work out the way I want them to." This scale had a Cronbach's alpha of 0.86 . The following formula was used to compute skewness: $\quad$ skew $=\frac{1}{N} \sum_{i=1}^{N}\left\lceil\frac{x_{i}-\bar{X}}{S D}\right]^{3}$

Where $x_{\mathrm{i}}$, is the set of scores of the individual members in the team, $\bar{X}$ is the mean, $S D$ is the standard deviation and $N$ is the number of members.

Conscientiousness. Goldberg's (1992) operationalization of this trait is based on ten Big-Five markers of conscientiousness. There is substantial evidence for the reliability and validity of Goldberg's markers of conscientiousness as well as the other Big-Five personality dimensions (e.g., Smith and Snell, 1996; Dwight et al., 1998; Zweig, 2004). Respondents were presented with a set of nine-step bipolar rating scales anchored by opposing traits (e.g., "organized" and "disorganized"). This scale had a Cronbach's alpha of 0.86. Skewness was computed using the aforementioned formula.

Psychological Safety. Edmondson's (1999) 7-item measure of psychological safety was used. Participants responded to each item using a 7-point agreement scale $(1=$ strongly disagree, $7=$ strongly agree). A sample item from the measure is "It is safe to take a risk on this 
team." The Cronbach's alpha for this scale was 0.72 . ICC and $\mathrm{Rwg}_{(\mathrm{j})}$ calculations $\left(\mathrm{ICC}_{1}=.10\right.$, $\mathrm{ICC}_{2}=.43$ and $\left.\mathrm{Rwg}_{(\mathrm{j})}=.94\right)$ support aggregation of this measure to the team level.

Team Potency. Guzzo et al.'s (1993) 7-item team potency scale was used. Participants responded to these questions on a 7-point agreement scale $(1=$ strongly disagree, $7=$ strongly agree). A sample item from the potency scale reads, "No task is too tough for our team." The Cronbach's alpha for this scale was 0.92 . ICC and $\mathrm{Rwg}_{(\mathrm{i})}$ calculations $\left(\mathrm{ICC}_{1}=.24, \mathrm{ICC}_{2}=.67\right.$ and $\left.\mathrm{Rwg}_{(\mathrm{j})}=.97\right)$ support aggregation of this measure to the team level.

Team Performance. Team performance was assessed through faculty judges' ratings of each team's case presentation detailing a strategy for resolving the business problem. For each team, three faculty judges rated the presentation on eight items. Judges responded to each item on a 7-point scale. Sample items included, "How comprehensive and thorough was the analysis?" (1 = not at all comprehensive, 7 = very comprehensive) and "How would you rate the effectiveness of the proposed solution?" (1 = not at all effective, 7 = very effective). Judges' scores were averaged to create an overall score for each team. The Cronbach's alpha for this scale was 0.95 , and measures of interrater agreement revealed a high degree of interrater agreement $\left(\operatorname{Rwg}_{(\mathrm{j})}=.88\right)$.

Control Variables. Based on recommendations for the treatment of control variables (Bernerth and Aguinis, 2016), we included controls that were theoretically and empirically justified as potential alternative explanations for the relationships reported in this study. Prior research indicates that team size impacts the degree of cooperation within teams as well as the number and quality of ideas generated (Gallupe et al., 1992; Wagner, 1995); therefore, team size was included as a control variable. In addition, teams with members who have higher cognitive ability exhibit superior performance (Lepine, 2003). We capture cognitive ability using self- 
reported GPA of each team member. Finally, previous research examining the relationship between age diversity $(\mathrm{AD})$ and team outcomes has produced mixed results (Horwitz and Horwitz, 2007); therefore, we used standard deviation of age as a measure of objective AD.

\section{Results}

We explored our theorized model (Figure 1) using ordinary least squares (OLS) path analysis. We used PROC CALIS in SAS to estimate confidence intervals and effect sizes for indirect effects. Table 1 presents the means, standard deviations, and zero-order correlations for the study variables. Results of the path analysis appear in Table 2.

Tables 1 and 2

In Hypothesis 1, we propose a negative relationship between team negative affectivity and psychological safety. In support of this hypothesis, Table 1 shows that team negative affectivity is negatively correlated with psychological safety $(r=-.28, p<.01)$. The coefficient (Table 2 ) for the team negative affectivity $\rightarrow$ psychological safety path was also significant $(\beta=$ $-.34, p<.01)$, providing further support for Hypothesis 1 . Hypothesis 2 predicted a positive relationship between negative affectivity skewness and psychological safety after controlling for mean-level negative affectivity. In this instance, positive skew would imply a minority of high negative affectivity members and, thus, a beneficial influence on psychological safety. Although a directional test of the correlation displayed in Table 1 is supportive $(r=.22, p<.05)$, the coefficient for the negative affectivity skewness $\rightarrow$ psychological safety path was not statistically significant $(\beta=.10, p>.10)$. Hence, after controlling for mean-level negative affectivity (composition model), we find no evidence for an effect of a negative affectivity skewness (compilation model) on psychological safety. 
Hypothesis 3 predicts that team conscientiousness is positively related to psychological safety. A directional test of the correlation (Table 1) offers support for the hypothesis $(r=.22, p$ $<.05)$; however, the predicted conscientiousness $\rightarrow$ psychological safety path was only marginally significant $(\beta=.18, p=.054)$. Thus, results for Hypothesis 3 were mixed. Hypothesis 4 predicted a negative relationship between conscientiousness skewness and psychological safety after controlling for mean-level conscientiousness. Positive skew would imply a minority presence of high conscientiousness members, which is presumably unfavorable for psychological safety. Contrary to our prediction, the bivariate correlation $(r=.23, p<.10)$ and path coefficient $(\beta=.21, p<.05)$ suggest that team psychological safety increases with fewer rather than more team members high in conscientiousness. We address this counterintuitive finding in the discussion.

Hypotheses 5 and 6 depict the links among psychological safety, team potency, and team performance. Consistent with Hypothesis 5, the bivariate correlation $(r=.54, p<.01)$ and the psychological safety $\rightarrow$ team potency path coefficient $(\beta=.41, p<.01)$ indicate that ensuing levels of team potency captured during the second measurement period were elevated for teams characterized by high levels of psychological safety during the first measurement period. With regard to Hypothesis 6 , correlational $(r=.28, p<.05)$ as well as path analytic results $(\beta=.24, p$ $<.05)$ provide support for the hypothesized link between team potency (second measurement period) and team performance scores (third measurement period).

\section{Indirect Effects}

Simple mediational analysis was performed to determine whether negative affectivity and conscientiousness indirectly influence team potency through effects on psychological safety. As indicated in Table 3, the indirect effect of negativity affectivity to team potency (through 
psychological safety) was negative (-.2567 to -.0231) and significant, indicating elevated (mean) levels of negative affectivity are associated with diminished perceptions of team potency.

Table 3

\section{Supplemental Analyses}

Predictions based on our hypothesized model centered on the influence of negative affectivity and conscientiousness on the proximal team state of psychological safety. Supplementary tests were conducted to assess any direct effects of team personality, composition and compilation forms, on the more distal state of team potency. We also assessed whether the traits and psychological safety had direct relationships with team performance. Of the additional paths, only the link between negative affectivity (mean) and team potency was significant $(\beta=$ $-.27, p<.05)$. None of the remaining paths were significant. Figure 2 displays standardized coefficients for all hypothesized paths and the significant path identified in our supplemental analysis. Table 4 displays the coefficients, their standard errors, and test statistics for the complete path model.

Figure 2

Table 4

The theoretical rationale for compilation measures used in this study relied upon the notion of patterned emergence stemming from distributional asymmetry (i.e., skewness). We acknowledge that a variance-based (member heterogeneity) approach represents a viable alternative to our measure of compilation emergence. Hence, we conducted supplemental analyses that substituted negative affectivity and conscientiousness variance (standard deviation) 
for the original skewness measures of compilation. Although we detected no relationship between conscientiousness and psychological safety when using this alternative measure of compilation emergence, we did observe a significant positive relationship between negative affectivity (standard deviation) and psychological safety $(\beta=-.27, p<.05)$. This suggests that member diversity in negative affectivity is potentially beneficial to psychological safety.

A prior data screening analysis was conducted to assess the distribution of the constructs. A Shapiro-Wilk W test is commonly used as a normality test in many research studies. The closer the test is to one, the stronger the support for normality. The value of the Shapiro-Wilk W test for Negative Affectivity (Mean), Negative Affectivity (Skewness), Conscientiousness (Mean), Conscientiousness (Skewness), Psychological Safety, Team Potency, and Team Performances are $.987, .988, .975, .974, .991, .966$, and .973 , respectively. All these tests support that the distribution of each construct is approximately normally distributed at the $5 \%$ significance level. An additional analysis for the hypothesized path model was explored in which path coefficients between personality variables and team performance were included. However, none of these paths were significant and this alternative model was not considered to be a competitive model.

\section{Discussion}

Multilevel theorizing that describes how individual level traits combine to form team level traits focuses on two emergent processes: compositional and compilational. Kozlowski and Klein (2000) contend that team personality can emerge through either form or a hybrid of both. Our findings contribute to the theory by demonstrating that the influence of some team-level traits is contingent upon whether the underlying emergent process is compositional or compilational. On the one hand, based solely on the use of a mean-aggregated measure 
(composition perspective), results from our study largely support the expectation that merely boosting team-level conscientiousness has a positive impact on team functioning. However, based on skewness or distributional asymmetry (compilation perspective), the value of team conscientiousness achieved through an increasing number of conscientious members is subject to diminishing returns: too many conscientious members may be an impediment to psychologically safe team environments. On the other hand, our findings also indicate that effects of distributional asymmetry or skewness in team negative affectivity essentially match the effects of mean-level negative affectivity. Whether a team has elevated levels of negative affectivity or an increasing number of high negative affectivity members, both are detrimental to psychological safety. The mechanism underlying the effects of negative affectivity is likely the same for both forms of emergence. Specifically, research on emotional contagion demonstrates that moods are contagious such that team members can infect each other with their mood (Kelly and Barsade, 2001). Whether members have similar trait affective dispositions or experience similar affective stimuli (e.g., emotional leader or peer), the ensuing team affect has been shown to influence group attitudes (Barsade and Knight, 2015). Contrary to our predictions, skewness measures of negative affectivity failed to predict any variation in psychological safety beyond the standard mean-level composition measure. At the same time, supplemental analysis using a variancebased compilation measure indicates that after accounting for mean levels of negative affectivity within a team, increased member heterogeneity in this attribute is related to psychologically safe team environments.

\section{Implications}

The notion that too much conscientiousness is disadvantageous is counterintuitive. After all, meta-analytic relationships between team conscientiousness and team performance are 
positive, albeit reported effect sizes are small. (Prewett et al., 2009). Nonetheless, our study is not the first to contradict management lore that conscientiousness inevitably leads to positive results (Buckley et al., 2015). For instance, Le and colleagues (2011) found support for a curvilinear relationship between conscientiousness and job performance. Thus, beyond a certain inflection point increases in individual level conscientiousness do not result in higher performance. Also, high levels of conscientiousness may undermine other types of performance such as creativity (George and Zhou, 2001), and it may be accompanied by excessive levels of perfectionism (Stoeber and Otto, 2006).

Prior research findings notwithstanding, some distinguishing features of the current study may account for the contradictory effects we observed. First, the preponderance of meta-analytic data link team conscientiousness to more distal performance outcomes rather than team process variables. Second, meta-analytic findings are based largely on mean aggregated measures (composition form) of team conscientiousness; not the skewness measures (compilation form) employed in our study. Since composition and compilation phenomena emerge and manifest in different ways, the influence of team-level conscientiousness captured by compilation measures may deviate from findings based on composition measures. In effect, when capturing team conscientiousness, there is distinction between too much conscientiousness and too many conscientious members. Finally, models of conscientiousness propose anywhere between two to eight facets (Rikoon et al., 2016). The link between conscientiousness and psychological safety may depend upon which facets of conscientiousness are activated in the team setting. In this instance, one facet - perfectionism - may have dysfunctional effects on teamwork if team members have unreasonably high standards for their peers (Curşeu et al., 2018). In sum, for theoretical purposes, team researchers should be prepared to challenge the assumption that 
ostensibly beneficial team member traits such as conscientiousness merely have to coalesce to promote healthy team processes and outcomes.

Team member interactions and perceptions are shaped by individual differences. Given elevated levels of negative affectivity or a critical mass of high negative affectivity members, the quality of those interactions and perceptions likely reflects more distress, anxiety, and dissatisfaction, ceteris paribus. Data from the current study suggest that the aversive property of those interactions can be detrimental to the emergence of psychologically safe environments. Our findings complement a growing number of studies that draw attention to the harmful effects of negative behavior and relationships on team functioning (de Jong et al., 2014; Jaikumar and Mendonca, 2017). The potency of negative events is especially relevant to the development of high functioning teams. That is, the presence of high negative affectivity at the outset can taint the earliest experiences and contacts among team members. Our findings suggest that the corrupting effects are twofold. First, elevated team negative affectivity has a direct effect on team potency. Consistent with an information-processing view, we speculate that when members consider evidence of team progress and capabilities, prior negative affective experiences and contacts effectively bias the search in long-term memory to negative information. Limited to only negative information, judgments of potency are lower (see Gibson, 2003). Second, team negative affectivity influences potency indirectly by fostering psychologically unsafe team environments.

The practitioner literature has clearly recognized the import of psychological safety as firms seek to quantify what it takes to make teams work together (Woo, 2017). In concert with that view, our data demonstrate that early judgments of psychological safety have a pronounced influence on assessments of team potency at the latter phases of the team lifecycle. Given that 
team-level traits clearly influence those early judgments, organizations are well advised to consider the impact of specific traits when placing members on teams. Ultimately, the benefits of psychologically safe teams may stem from how those teams manage conflict. Both sequential (Tuckman, 1965) and non-sequential (Gersick, 1988) models of group development hold that members must feel comfortable working with teammates before transitioning to a performance phase. Moreover, research findings suggest that effective teams tend to resolve conflict by explicitly discussing issues (Behfar et al., 2008). Of course, resolving conflict in this manner presupposes the willingness of team members to discuss contentious issues and their openness to hearing different ideas. In effect, "seeding" teams with specific traits is one means of creating psychologically safe environments during the early phases of the team lifecycle. That is, carefully managed team staffing practice that consider team personality could assure members' willingness to address contentious topics, resolve conflicts, and direct efforts toward task completion.

\section{Future Directions}

Our research, while shedding light on the ramifications of the aggregation technique utilized to explore the effects of personality traits on emergent states at the team level, does not explore cross-level interactions. Consequently, future research should explore how the team influences the individual members of the team, utilizing both composition and compilation approaches and building several other multi-level studies that examine personality within teams (e.g., Beus et al., 2015; Prewett et al., 2018; Xu et al., 2019). Additionally, future research should study additional individual differences, to test if the aggregation approach utilized also results in different findings. Lastly, future research should test these effects with an organizational sample. 


\section{Limitations}

Some limitations in our study warrant caution in the interpretation of the results. First, the student sample clearly limits generalizability of the results. Nevertheless, the nature of the team tasks, performance requirements and incentives, and the temporary character of these teams are consistent with project teams in employment settings. Second, while small sample sizes are common in team research, with additional observations, some marginal relationships (e.g., conscientiousness (mean) $\rightarrow$ psychological safety) may have reached statistical significance. Finally, while the measurement intervals between psychological safety, team potency, and performance coupled with the use of independent judges are strong points, the performance measure used in this study was deficient because it was based on a single episode of performance (i.e., case presentation) rather than the overall performance of each team.

\section{Conclusions}

In conclusion, a primary contribution of this study lies in distinguishing compilation and composition perspectives used to conceptualize the emergence and influence of personality traits at the team level. The assumed process by which team traits emerge differs for mean-aggregated (composition) and skewness (compilation) measures. With the former, team personality reflects a convergence of trait-related perceptions, cognitions, and behaviors; whereas the latter suggests that a critical bloc of individual members give rise to team personality. Either process may be relevant to how team personality manifests, yet results from this investigation suggest that the weight of composition and compilation emergence is contingent upon the trait. Detriments in psychological safety were related to mean-levels of negative affectivity; distributional asymmetry (skewness) failed to account for additional variation in psychological safety. In contrast, the use of skewed conscientiousness brought an undetected and counterintuitive 
relationship to light that suggests too many highly conscientious members can be detrimental to psychological safety. Our findings also underscore the importance of negative affectivity, a potentially destructive, dark side attribute capable of derailing the emergence of psychological safety and team potency. Lastly, we see that a team's sense of competency or potency, an emergent team state with strong links to performance, begins with the establishment of psychologically safe environments whereby members readily disclose information, address problems, request help, and accept mistakes. 


\section{References}

Barrick, M. R., and Mount, M. K., 1991. The Big Five personality dimensions and job performance: A meta-analysis. Personnel Psychology, 44(1), pp.1-26.

Barrick, M. R., Stewart, G. L., Neubert, M. J., and Mount, M. K., 1998. Relating member ability and personality to work-team processes and team effectiveness. Journal of Applied Psychology, 83, pp.377-391.

Barsade, S. G., \& Knight, A. P.,2015. Group Affect. The Annual Review of Organizational Psychology and Organizational Behavior, 2, pp.21-46.

Behfar, K. J., Peterson, R. S., Mannix, E. A., and Trochim, W. M., 2008. The critical role of conflict resolution in teams: A close look at the links between conflict type, conflict management strategies, and team outcomes. Journal of Applied Psychology, 93, pp.170188.

Bell, S., 2007. Deep-level composition variables as predictors of team performance: A metaanalysis. Journal of Applied Psychology, 92, pp.595-615.

Bernerth, J. B., and Aguinis, H., 2016. A critical review and best-practice recommendations for control variable usage. Personnel Psychology, 69, pp.229-283.

Beus, J.M., Muñoz, G.J. and Arthur Jr, W., 2015. Personality as a multilevel predictor of climate: An examination in the domain of workplace safety. Group \& Organization Management, 40(5), pp.625-656.

Bliese, P. D., 2000. Within-group agreement, non-independence, and reliability: Implications for data aggregation and analysis. In K. J. Klein and S. W. J. Kozlowski (Eds.), Multilevel Theory, Research, and Methods in Organizations (pp. 349-381). San Francisco, CA: Jossey-Bass. 
Bradley, B.H., Postlethwaite, B.E., Klotz, A.C., Hamdani, M.R. and Brown, K.G., 2012. Reaping the benefits of task conflict in teams: The critical role of team psychological safety climate. Journal of Applied Psychology, 97(1), pp.151.

Buckley, M. R., Baur, J. E., Hardy, J. H., Johnson, J. F., Johnson, G. MacDougall, A. E.,...Peacock, J., 2015. Management lore continues alive and well in the organizational sciences. Journal of Management History, 21, pp.68-97.

Costa, P. T., \& McCrae, R. R., 1992. Revised NEO Personality Inventory (NEO-PIR): Professional manual. Odessa, FL: Psychological Assessment Resources.

Curşeu, P. L., Ilies, R., Vîrgă, D., Maricuţoiu, L., and Sava, F. A., 2019. Personality characteristics that are valued in teams: Not always "more is better"? International Journal of Psychology, 54(5), pp.638-649.

de Jong, J. P., Curseu, P. L., and Leenders, R., 2014. When do bad apples not spoil the barrel? Negative relationships in teams, team performance, and buffering mechanisms. Journal of Applied Psychology, 99, pp.514-522.

Dudley, N.M., Orvis, K.A., Lebiecki, J.E. and Cortina, J.M., 2006. A meta-analytic investigation of conscientiousness in the prediction of job performance: examining the intercorrelations and the incremental validity of narrow traits. Journal of Applied Psychology, 91(1), pp.40.

Dwight, S. A., Cummings, K. M., \& Glenar, J. L., 1998. Comparison of Criterion-Related Validity Coefficients for Mini-Markers and Goldberg's Markers of the Big Five Personality Factors. Journal of Personality Assessment, 70(3), pp.541-550.

Edmondson, A., 1999. Psychological safety and learning behavior in teams. Administrative Science Quarterly, 44, pp.350-383. 
Felps, W., Mitchell, T., and Byington, E., 2006. How, when, and why bad apples spoil the barrel: Negative group members and dysfunctional groups. Research in Organizational Behavior, 27, pp.175-222.

Frazier, M. L., Fainshmidt, S., Klinger, R. L., Pezeshkan, A., and Vracheva, V., 2017. Psychological safety: A meta-analytic review and extension. Personnel Psychology, 70, pp.113-165.

Gallupe, R. B., Dennis, A. R., Cooper, W. H., Valacich, J. S., Bastianutti, L. M., and Nunamaker, J. F., 1992. Electronic brainstorming and group size. Academy Of Management Journal, 35, pp.350-369.

George, J. M., and Zhou, J., 2001. When job dissatisfaction leads to creativity: Encouraging the expression of voice. Academy of Management Journal, 44, pp.682-696.

Gersick, C. J., 1988. Time and transition in work teams: Toward a new model of group development. Academy of Management Journal, 31, pp.9-41.

Gibson, C. B., 2003. The efficacy advantage: Factors related to the formation of group efficacy. Journal of Applied Social Psychology, 33, pp.2153-2186.

Goldberg, L. R., 1992. The development of markers for the Big-Five factor structure. Psychological Assessment, 4(1), pp.26-42.

Gonzalez-Mulè, E., DeGeest, D. S., McCormick, B. W., Seong, J. Y., and Brown, K. G., 2014. Can we get some cooperation around here? The mediating role of group norms on the relationship between team personality and individual helping behaviors. Journal of Applied Psychology, 99, pp.988-999. 
Gully, S.M., Incalcaterra, K. A., Joshi, A., and Beaubien, J. M., 2002. A meta-analysis of teamefficacy, potency, and performance: Interdependence and level of analysis as moderators of observed relationships. Journal of Applied Psychology, 87, pp.819-832.

Guzzo, R. A., Yost, P.R., Campbell, R.J., and Shea, G.P., 1993. Potency in groups: articulating a construct. British Journal of Social Psychology, 32, pp.87-106.

Hair, J.F., Black, W.C., Babin, B.J., Anderson, R.E. and Tatham, R.L., 2006. Multivariate data analysis, $6^{\text {th }}$ edition. Upper Saddle River, NJ: Prentice hall.

Hobfoll, S. E., 1988. The ecology of stress. Washington DC: Hemisphere Publishing.

Hogan, L. M., and Ones, D. S., 1997. Conscientiousness and integrity at work. In R. Hogan, J. A. Johnson, \& S. R. Briggs (Eds.), Handbook of personality psychology (pp. 849-870). San Diego, CA: Academic Press.

Hood, A. C., Bachrach, D. G., Zivnuska, S., and Bendoly, E., 2016. Mediating effects of psychological safety between team affectivity and transactive memory systems. Journal of Organizational Behavior, 37, pp.416-435.

Horwitz, S. J., and Horwitz, I. B., 2007. The effects of team diversity on team outcomes: A meta-analytic review of team demography. Journal of Management, 33, pp.987-1015.

Hu, J. and Liden, R.C., 2011. Antecedents of team potency and team effectiveness: An examination of goal and process clarity and servant leadership. Journal of Applied Psychology, 96(4), pp.851.

Humphrey, S. E., Hollenbeck, J. R., Meyer, C. J., and Ilgen, D. R., 2007. Trait configurations in self-managed teams: a conceptual examination of the use of seeding for maximizing and minimizing trait variance in teams. Journal of Applied Psychology, 92, pp.885-892. 
Humphrey, S.E., Hollenbeck, J.R., Meyer, C.J. and Ilgen, D.R., 2011. Personality configurations in self-managed teams: A natural experiment on the effects of maximizing and minimizing variance in traits. Journal of Applied Social Psychology, 41(7), pp.17011732.

Hurtz, G. M., and Donovan, J. J., 2000. Personality and job performance: The Big Five revisited. Journal of Applied Psychology, 85, pp.869-879.

Ilgen, D. R., Hollenbeck, J. R., Johnson, M., and Jundt, D., 2005. Teams in organizations: From input-process-output models to IMOI models. Annual Review of Psychology, 56, pp.517543.

Jaikumar, S., and Mendonca, A., 2017. Groups and teams: A review of bad apple behavior. Team Performance Management: An international journal, 23(5/6), pp.243-259.

James, L. R., Demaree, R. G., and Wolf, G., 1984. Estimating within-group interrater reliability with and without response bias. Journal of Applied Psychology, 69, pp.85-98.

Kaplan, S., Bradley, J.C., Luchman, J.N. and Haynes, D., 2009. On the role of positive and negative affectivity in job performance: A meta-analytic investigation. Journal of Applied Psychology, 94(1), pp.162.

Kayes, A., Kayes, D. C., and Kolb, D. A., 2005. Experiential learning in teams. Simulation and Gaming, 36, pp.330-354.

Kelly, J. R., \& Barsade, S. G., 2001. Mood and emotions in small groups and work teams. Organizational Behavior and Human Decision Processes, 86, pp.99-130.

Kozlowski, S. W. J., and Chao, G. T., 2012. The dynamics of emergence: Cognition and cohesion in work teams. Managerial and Decision Economics, 33, pp.335-354. 
Kozlowski, S. W. J. and Ilgen, D. R., 2006. Enhancing the effectiveness of work groups and teams. Psychological Science in the Public Interest, 7, pp.77-124.

Kozlowski, S. W. J. and Klein, K. J., 2000. A multilevel approach to theory and research in organizations: Contextual, temporal, and emergent processes. In K. J. Klein and S. W. J. Kozlowski (Eds.), Multilevel Theory, Research, and Methods in Organizations (pp. 390). San Francisco, CA: Jossey-Bass.

Le, H., Oh, I., Robbins, S. B., Ilies, R., Holland, E., and Westrick, P., 2011. Too much of a good thing: Curvilinear relationships between personality traits and performance. Journal of Applied Psychology, 96, pp.113-133.

LePine, J. A., 2003. Team adaptation and postchange performance: Effects of team composition in terms of members' cognitive ability and personality. Journal of Applied Psychology, 88, pp.27-39.

Levin, I., and Stokes, J. P., 1989. Dispositional approach to job satisfaction: Role of negative affectivity. Journal of Applied Psychology, 74, pp.752-758.

Levine, E. L. and Xu, X., 2005. Development and Validation of the State Trait Emotion Measure (STEM) the 20th Annual Conference of the Society for Industrial and Organizational Psychology, April 2005, Los Angeles.

Mannix, E., and Neale, M. A., 2005. What differences make a difference? The promise and reality of diverse teams in organizations. Psychological Science in the Public Interest, 6, pp.31-55.

Marks, M. A., Mathieu, J. E., and Zaccaro, S. J., 2001. A temporally based framework and taxonomy of team processes. Academy of Management Review, 26, pp.356-376. 
Mathieu, J., Maynard, M. T., Rapp, T., and Gilson, L., 2008. Team effectiveness 1997-2007: A review of recent advancements and a glimpse into the future. Journal of Management, 34 , pp.410-476.

Moon, H., 2001. The two faces of conscientiousness: Duty and achievement striving in escalation of commitment dilemmas. Journal of Applied Psychology, 86, pp.533-540.

Moynihan, L. M., and Peterson, R. S., 2001. A contingent configuration approach to understanding the role of personality in organizational groups. In B. M Staw \& R. I. Sutton, (Eds.), Research in Organizational Behavior, 23, pp.327-378.

Pearce, C. L., Gallagher, C. A., and Ensley, M. D., 2002. Confidence at the group level of analysis: A longitudinal investigation of the relationship between potency and team effectiveness. Journal of Occupational and Organizational Psychology, 75, pp.115-119.

Podsakoff, P. M., MacKenzie, S. B., and Podsakoff, N. P., 2012. Sources of method bias in social science research and recommendations on how to control it. Annual Review of Psychology, 63, pp.539-569.

Prewett, M.S., Brown, M.I., Goswami, A. and Christiansen, N.D., 2018. Effects of team personality composition on member performance: A multilevel perspective. Group \& Organization Management, 43(2), pp.316-348.

Prewett, M. S., Walvoord, A. A., Stilson, F. R. B., Rossi, M. E., and Brannick, M. T., 2009. The team personality-team performance relationship revisited: The impact of criterion choice, pattern of workflow, and method of aggregation. Human Performance, 22, pp.273-296. 
Raver, J. L., Ehrhart, M. G., and Chadwick, I. C., 2012. The emergence of team helping norms: Foundations within members' attributes and behavior. Journal of Organizational Behavior, 33, pp.616-637.

Sinha, R. Janardhanan, N. S., Greer, L. L., Conlon, D. E., and Edwards, J. R., 2016. Skewed task conflicts in teams: What happens when a few members see more conflict than the rest? Journal of Applied Psychology, 101, pp.1045-1055.

Smith, D. R., and Snell, W. E., 1996. Goldberg's bipolar measure of the Big-Five personality dimensions: Reliability and validity. European Journal of Personality, 10(2), pp.283299.

Stajkovic, A. D., Lee, D., and Nyberg, A. J., 2009. Collective efficacy, group potency, and group performance: Meta-analyses of their relationships, and test of a mediation model. Journal of Applied Psychology, 94, pp.814-828.

Stewart, G. L., 2003. Toward an understanding of the multilevel role of personality in teams. In M. R. Barrick \& A. M. Ryan (Eds.), Personality and work: Reconsidering the role of personality in organizations (pp. 183-204). San Francisco: Jossey-Bass.

Stoeber, J., and Otto, K., 2006. Positive conceptions of perfectionism: Approaches, evidence, challenges. Personality and Social Psychology Review, 10, pp.295-319.

Stokes, J. P. and Levine, I. M., 1990. The development and validation of a measure of negative affectivity. Journal of Social Behavior and Personality, 5(2), pp.173-196.

Sukhodolsky, D. G., Golub, A., and Cromwell, E. N., 2001. Development and validation of the anger rumination scale. Personality and Individual Differences, 31, pp.689-700.

Tuckman, B. W., 1965. Developmental sequences in small groups. Psychological Bulletin, 63, pp.384-399. 
Wagner, J. A., 1995. Studies of individualism-collectivism: Effects on cooperation in groups. Academy of Management Journal, 38, pp.152-172.

Watson, D., and Clark, L. A., 1984. Negative affectivity: The disposition to experience aversive emotional states. Psychological Bulletin, 96, pp.465-490.

Watson, D., Clark, L. A., and Tellegen, A., 1988, "Development and validation of brief measures of positive and negative affect: The PANAS scales". Journal of Personality and Social Psychology, 54(6), pp.1063-1070.

Woo, S. (2017, Mar 13), Workplace technology (A special report) - In search of a perfect team: Who works best with whom? Now we know. Wall Street Journal. Retrieved from https://search.proquest.com/docview/1876329827?accountid=7113

Wyss-Flamm, E. D., 2002. Conversational learning and psychological safety in multicultural teams. Unpublished doctoral dissertation, Case Western Reserve University, Cleveland, OH. Retrieved from https://search.proquest.com/docview/287881320?accountid=7113

Xu, X., Le, N., He, Y. and Yao, X., 2019. Team Conscientiousness, Team Safety Climate, and Individual Safety Performance: a Cross-Level Mediation Model. Journal of Business and Psychology, pp.1-15.

Zweig, D., 2004. What are we measuring? An examination of the relationships between the bigfive personality traits, goal orientation, and performance intentions. Personality and Individual Differences, 36(7), pp.1693-1708. 


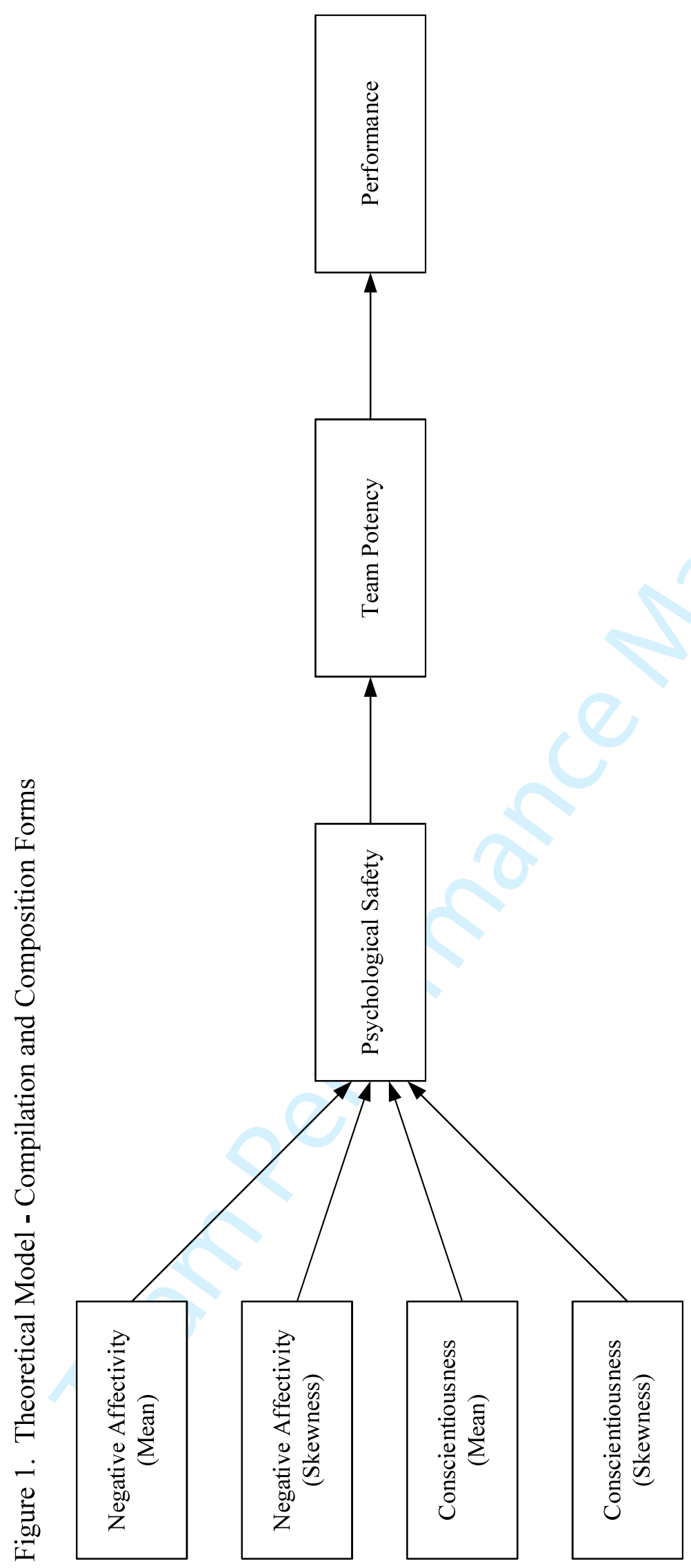

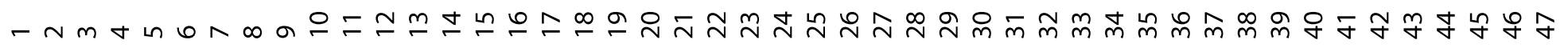




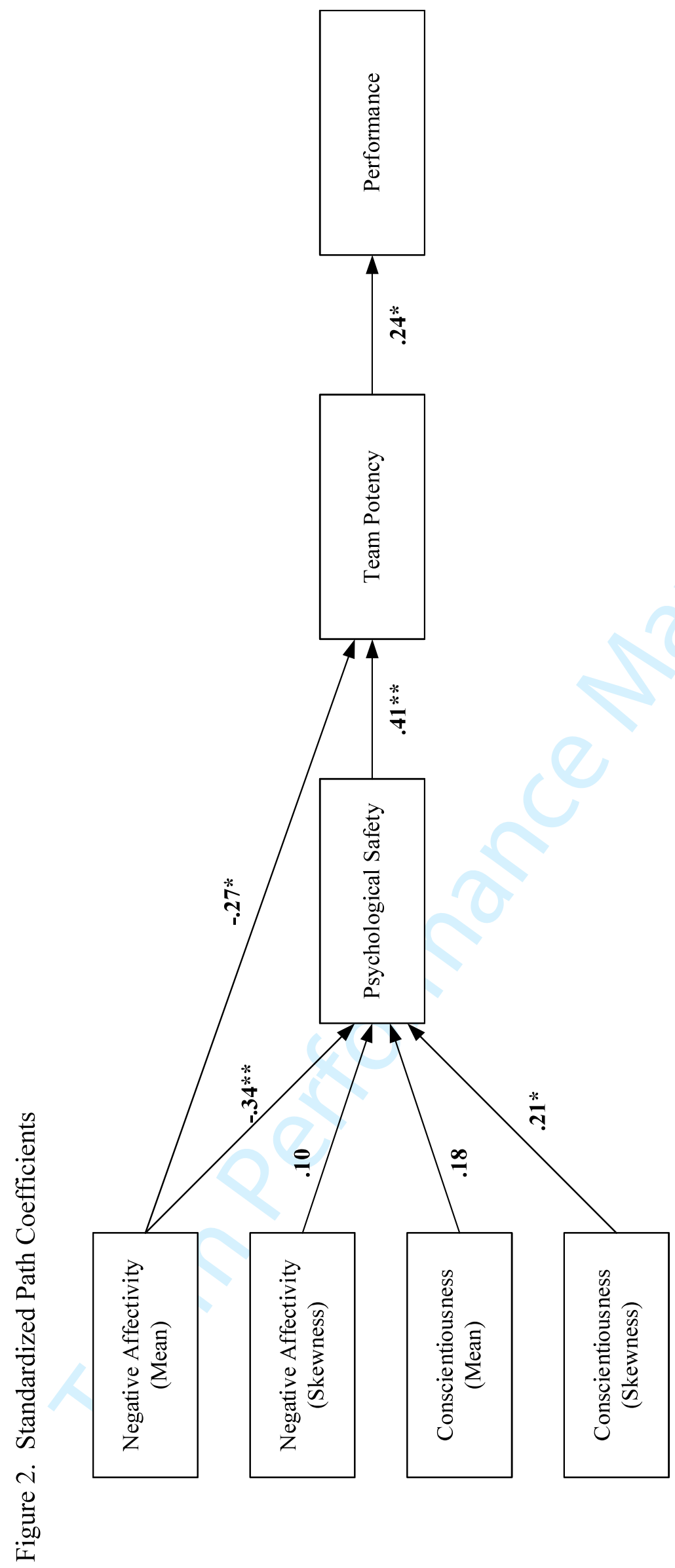

3 


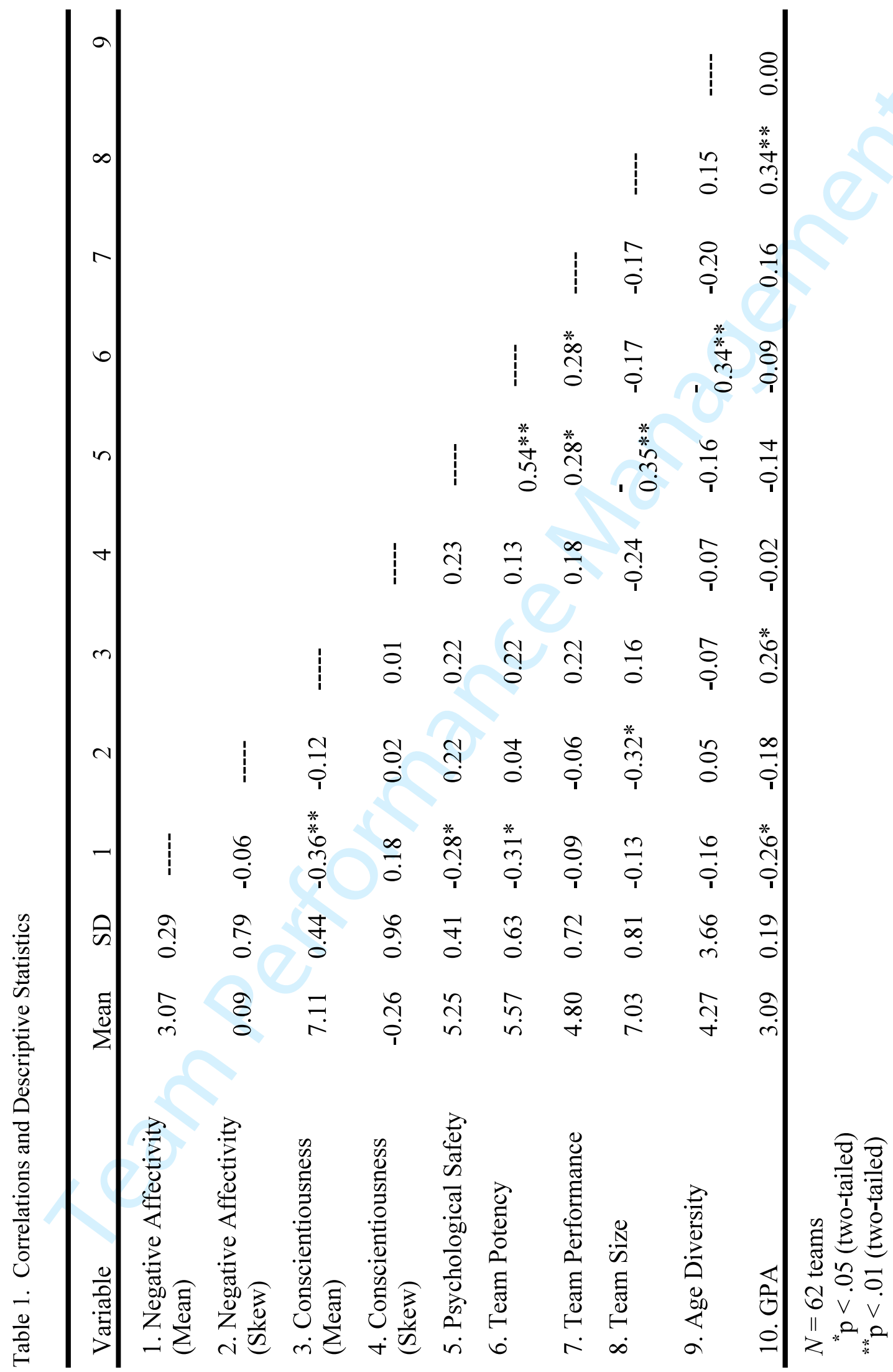




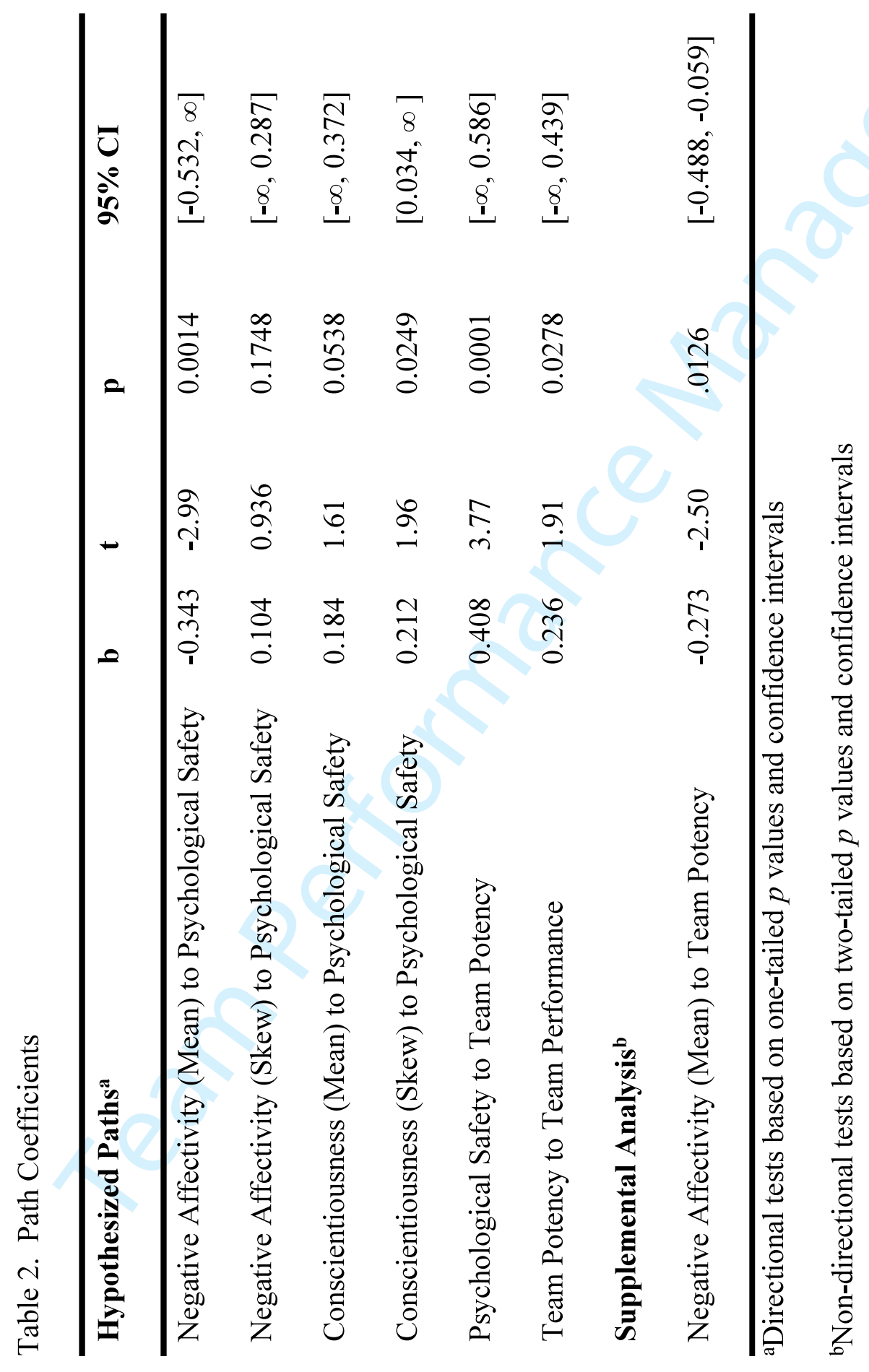




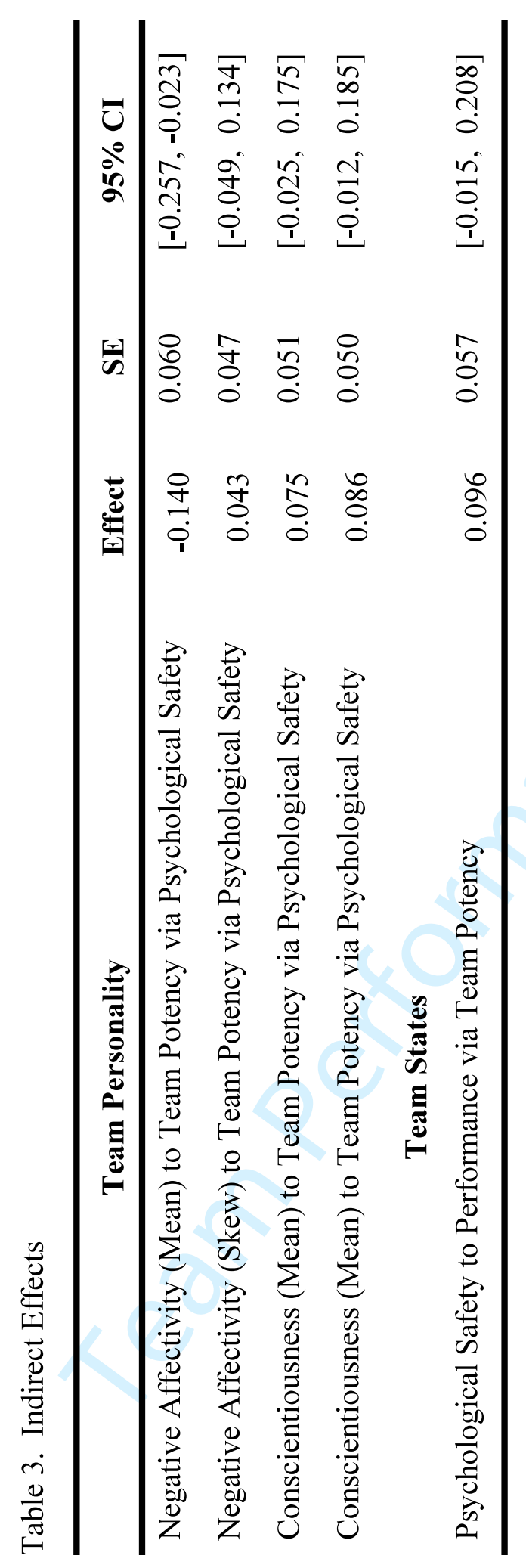

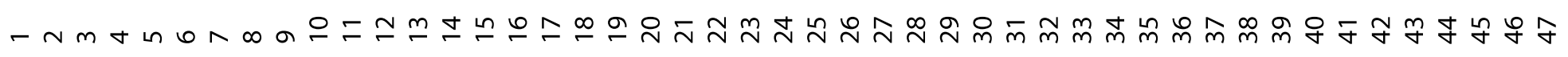




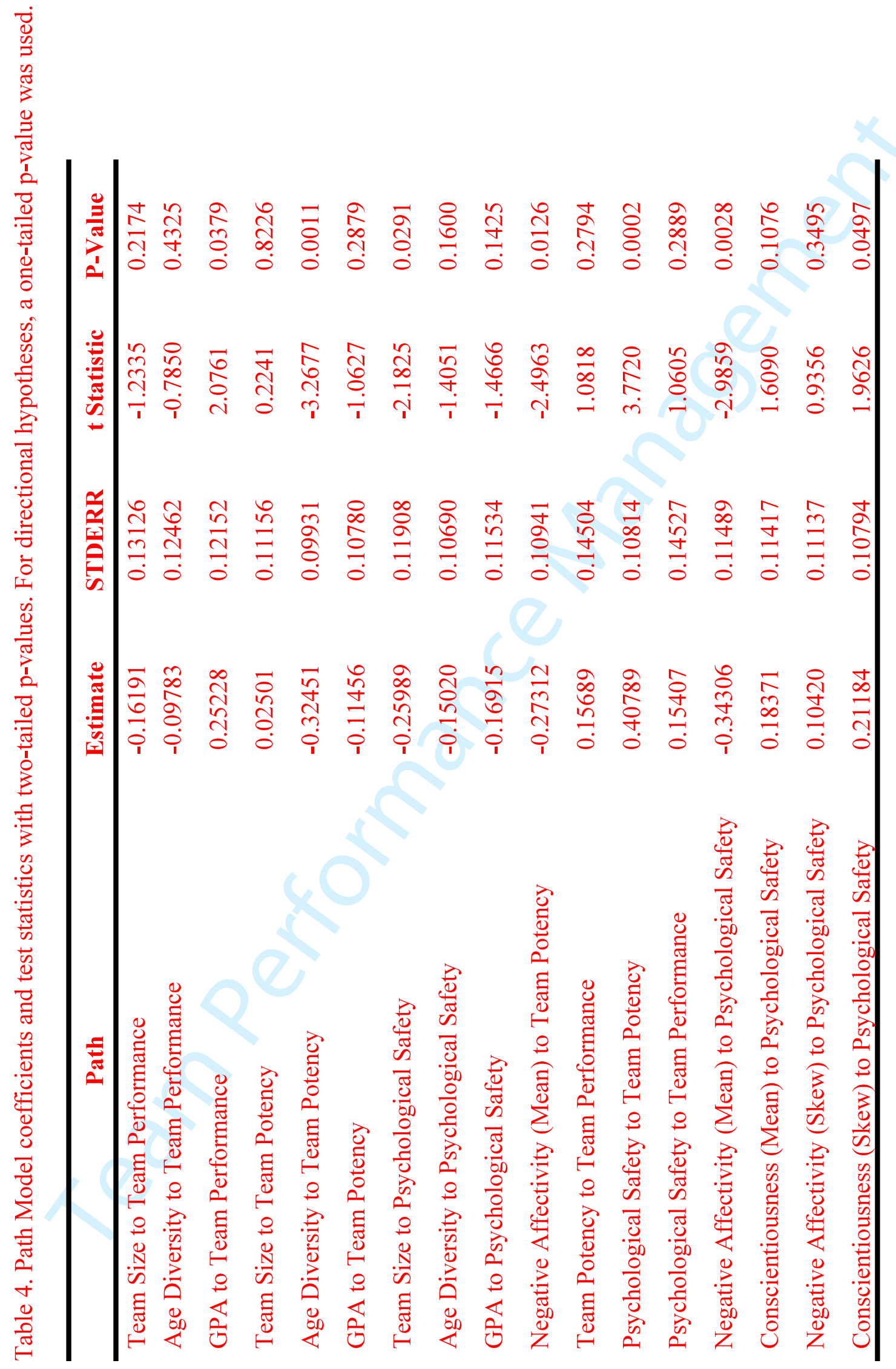

